\title{
Simple visual and simple auditory reaction time: A comparison'
}

ROGERS ELLIOTT

DARTMOUTH COLLEGE

In two experiments the classically reported difference of about 40 msec between simple $R T$ s to high intensity tone and light wias reproduced using $1^{o}$ and $3^{\circ}$ targets, but was reduced to 24 msec by illuminating virtually the whole retinal surface. In a third experiment, the indicated relations between target size and $R T$ were repeated.

Woodworth (1938, ch. 14) and Woodworth \& Schlosberg $(1954$, ch. 2$)$, in their reviews of the literature on simple reaction time (RT) state by way of summary that among well-practiced Ss RTs to acoustic and tactual stimuli of moderate intensity approximate $140 \mathrm{msec}$ while those to visual stimuli average about $180 \mathrm{msec}$. Simple RT is well established as being dependent upon stimulus intensity, and the problem of comparing intensities from one modality to another is difficult, as Woodworth noted. But he suggested that if the RTs in each modality are obtained at intensity levels at which speed is asymptotically fast, then one can fairly compare one modality with another with respect to RT. Since such intensity levels are customary in RT work, he stated, the $40 \mathrm{msec}$ difference between visual and auditory RT was probably valid, and Woodworth and Schlosberg suggested that most or all of this difference might be accounted for by the longer time taken by photoreception as compared with mechanical stimulation at the ear.

Even with the use of intensities yielding asymptotically fast RTs, the difference of $40 \mathrm{msec}$ is probably too large, for two reasons. First, as the reviews cited above clearly point out, visual RTs are an inverse function of the area of retinal stimulation, at least up to $15-20^{\circ}$ of visual angle. Second, if the visual stimulus is a target of limited size, say a few degrees of visual angle, then the eye has a requirement notimposed upon the ear (or on the skin in the case of tactual stimuli), that of maintaining receptor orientation. If the eye is not fixated on the target, then the stimulus will hit peripheral areas known to yield slower RTs than does the foveal area (if, as is the usual case, the eye is not dark-adapted).

No one has attempted to illuminate virtually the whole of the retinal surface in assessing visual RT. The present experiments were designed to do that using sound and light stimuli of high intensity which, when employed in a classical way (i.e., using relatively small visual targets) yielded the classical difference between auditory and visual RT.

Method

Subjects. The Ss were all male undergraduates.
The two Ss in Experiment 1 and the four Ss in Experiment 3 were each paid $\$ 1.50$ per session. The five Ss in Experiment 2 were given extra course credit for participation.

Apparatus. The laboratory space was a $12 \times 6 \mathrm{ft}$ room illuminated by a $100 \mathrm{~W}$ overhead bulb within a milkglass fixture. The RT system consisted of five Hunter interval timers, a stepping switch, two HewlettPackard audio-oscillators, Knight stereo earphones, a Hewlett-Packard Model 552B electronic counter, a Welch color mixer, an electronic flashgun, and a microswitch "reaction key" attached to the desk surface of a classroom writing chair.

Procedure. In all three experiments, Ss were run in one prelininary adaptation and four regular sessions. In each regular session of Experiment 1 each $S$ reacted under four conditions: auditory (A), wide-angle visual flash (VF), $1^{\circ}$ visual target (VT1), and $1^{\circ}$ visual target $18^{\circ}$ temporally peripheral (on the retina) to the fixation point along the horizontal meridian (VT1p). The order of conditions was changed each day and balanced, and within each day the order was reversed halfway through the session so that in each session there were eight blocks of 20 reactions each.

Experiment 2 was undertaken to repeat, if possible, the results of Experiment 1, and to assess the effects of changing the visual target size from $1^{\circ}$ to $3^{\circ}$, so that the conditions were A, VF, and VT3. Experiment 3 was done to put both the $1^{\circ}$ and the $3^{\circ}$ visual targets into the same experiment. The conditions were A, VF, VT1, and VT3, but at the end of the experiment it transpired that the gain on the oscillator had been lowered at some point, making comparison with the A condition of the other two experiments impossible. Only the visual RTs are presented. In Experiments 2 and 3, the number of trials in a block of reactions was reduced from 20 to 15.

In any condition, the $S$ initiated a trial by pressing the key of the microswitch fastened to his desk, thus closing a circuit which initiated a delay interval set into one of the timers. The five delay intervals were $1.4,1.7,2.0$, 2.3 , and $2.6 \mathrm{sec}$, and one of these was selected on each trial by a stepping switch programmed in a quasirandom sequence of 44 steps. After the delay, the audio-oscillator or flashgun and the electronic counter (functioning as a msec timer) were impulsed, and the S's lifting of the key then stopped the counter. The $\mathrm{E}$ then recorded the time, selected the next delay interval, and told the $S$ to begin the next trial when ready.

In the A condition, the stimulus was a $1000 \mathrm{cps}$ tone delivered binaurally at about $80 \mathrm{~dB}$ above normal thresh- 
old. The tone continued until the $S$ reacted. In all the visual conditions, the S's head rested against a forehead board which put his eye 6 in. from the center of the frosted glass front of the color mixer. During visual trials, $S$ heard a continuous masking tone $(400 \mathrm{cps})$ through the earphones, and had cotton in his ears. Viewing was monocular, the left eye being covered with an eye patch. The flashgun, when impulsed, gave an instantaneous, brief, extremely bright light.

In the VF condition, the entire front surface of the color mixer was lighted, creating a very large "target" with a visual angle of about $80^{\circ}$. The Ss were told to look at a small mark at the center of the glass. In the VT1 condition, the glass was covered with a medium gray cardboard, and the target was a $1^{\circ}$ hole in the center of it, on which the Ss were told to fixate. In the VT1p condition, the same target was used, but the $S$ was told to fixate a dot on the cardboard screen $18^{\circ}$ to the right of the target.

Analysis. For each of the last two sessions and for each S, the 40 RTs for each condition were entered into a simple 1 by 4 analysis of variance, and then into pairwise $t$ test comparisons. These analyses assumed each $\mathrm{S}$ to be a population of RTs, and the $t$ tests therefore assumed independence from condition to condition. Since the results from the last two days were near replicas, one of the other, only the data from the last session is presented.

\section{Results and Discussion}

Table 1-1 shows the relevant data for Experiment 1. The A condition yielded RTs about $24 \mathrm{msec}$ faster than the VF condition, which was, in turn, about $17 \mathrm{msec}$ faster than the VT1 condition, for a total, manifest in each S, of a $41 \mathrm{msec}$ difference between A and VT1. The Ss were slower still when the $1^{\circ}$ target was viewed peripherally, another classical finding. In general, the expectations were confirmed.

Table 1-2 contains the data of Experiment 2. While these five Ss were in general faster than the two Ss of Experiment 1, there was still about $24 \mathrm{msec}$ difference between the $\mathrm{A}$ and $\mathrm{VF}$ conditions. The difference between the VF and the VT3 conditions was only about $12 \mathrm{msec}$, slightly less than the $17 \mathrm{msec}$ difference found when the target was only $1^{\circ}$, as would be expected with the increase in target size.

Table 1-3 presents the results of Experiment 3. The average RT of these four Ss to the VF condition was about $170 \mathrm{msec}$, very close to the average of $171 \mathrm{msec}$ for the seven Ss of Experiments 1 and 2. The increment in RT caused by reducing target size from the wide-angle flash to $3^{\circ}$ was $10 \mathrm{msec}$, compared with the $12 \mathrm{msec}$ difference in Experiment 2. The difference between VF and VT1 was $21 \mathrm{msec}$, compared with the corresponding difference of $17 \mathrm{msec}$ in Experiment 1.

The data from the three experiments can be sum-
Table 1. Average RT of Each $S$ in the Various Conditions of the Three Experiments.

\begin{tabular}{ccccc} 
& \multicolumn{5}{c}{ Experiment 1} \\
Subjects & A & VF & VT 1 p & VT 1 \\
\hline S1 & 157 & $182 \mathrm{a}$ & $216 \mathrm{a}$ & $198 \mathrm{a}$ \\
S2 & 155 & $178 \mathrm{a}$ & $208 \mathrm{a}$ & $196 \mathrm{a}$ \\
\hline Mean & 156 & 180 & 212 & 197 \\
\hline
\end{tabular}

Experiment 2

\begin{tabular}{cllll} 
Subjects & A & VF & VT3 & VT1 \\
\hline S1 & 151 & 180 & 185 & \\
S2 & 145 & $171 \mathrm{a}$ & $181 \mathrm{a}$ & \\
S3 & 135 & $163 \mathrm{a}$ & $188 \mathrm{a}$ & \\
S4 & 138 & $160 \mathrm{a}$ & $170 \mathrm{a}$ & \\
S5 & 152 & $164 \mathrm{a}$ & $178 \mathrm{a}$ & \\
\hline Mean & 144 & 168 & 180 \\
\hline
\end{tabular}

Experiment 3

\begin{tabular}{|c|c|c|c|c|}
\hline Subjects & A & VF & VT3 & VTI \\
\hline S1 & & $169 \mathrm{a}$ & $178 \mathrm{a}$ & 191 a \\
\hline S2 & & $181 \mathrm{a}$ & $180 \mathrm{~b}$ & $193 \mathrm{ab}$ \\
\hline S3 & & $155 \mathrm{a}$ & 168 & $177 \mathrm{a}$ \\
\hline$\$ 4$ & & $174 \mathrm{ab}$ & $194 \mathrm{~b}$ & $202 \mathrm{a}$ \\
\hline Mean & & 170 & 180 & 191 \\
\hline
\end{tabular}

Note: In each row, the mean in the $A$ condition is significantly different at less than the .01 level from the means in the other conditions. For the visual conditions, significant differences $(p<.05$, two-tailed) between pairs of means in the same row exist when each member of the pair has a common letter following it.

marized roughly as follows. If the A condition produces average RTs of $147 \mathrm{msec}$, the VF condition will produce latencies about $24 \mathrm{msec}$ longer, at 171. The VT3 condition is slower than the VF by about $11 \mathrm{msec}$, and the VT1 slower than the VT3 by another 8 or $9 \mathrm{msec}$. It is probably true that each size of visual target employed in an experiment will yield a negatively accelerating curve of RT by Intensity, and that the asymptote will be lower as the target angle increases. Therefore, apart from the time representing the difference in transduction of stimuli in the two modalities (photoreception taking longer), a "typical" difference between auditory and visual RT cannot be said to exist.

References

WOODWORTH, R. S. Experimental psychology. New York: Holt, 1938 WOODWORTH, R. S., \& SCHLOSBERG, H. Experimental psychology. New York: Holt, 1954

Note

1. This study was supported by Grant HD 01571 from the National Institute of Child Health and Human Development, USPHS. I wish to thank S. Goodman and K. Sorlein for their help in collecting the data, and W. L. Gulick for his helpful suggestions. 